\title{
Cardiovascular Risk Factors in the Civil Service of Oyo State, South-Western Nigeria: An Epidemic with an Unmatched Response
}

\section{Olaniyan Akintunde Babatunde ${ }^{1,2^{*}}$, Sunday Olakunle Olarewaju ${ }^{3}$, Adeleye Abiodun Adeomi ${ }^{4}$, Joel Olufunminiyi Akandes, Sunday Thomas Sola', Adenike Iyanuoluwa Olugbenga-Bello', James 0. Bamidele ${ }^{7}$}

\author{
${ }^{1}$ Department of Community Medicine, Ladoke Akintola University of Technology, Ogbomoso, Oyo State, Nigeria \\ ${ }^{2}$ Oriire Local Government Health Authority, Ikoyi-Ile, Oyo State, Nigeria \\ ${ }^{3}$ Department of Community Medicine, Osun State University, Osogbo, Osun State, Nigeria \\ ${ }^{4}$ Department of Community Medicine, Obafemi Awolowo University, Ile-Ife, Osun State, Nigeria \\ ${ }^{5}$ Department of Chemical Pathology, BOWEN University Teaching Hospital, Ogbomoso, Oyo State, Nigeria \\ ${ }^{6}$ Nigeria Field Epidemiology and Laboratory Training Programme, Asokoro, Abuja, Nigeria \\ ${ }^{7}$ Department of Community Medicine, Ekiti State University, Ado-Ekiti, Ekiti State, Nigeria \\ Email: ^tundebabson23@gmail.com
}

How to cite this paper: Babatunde, O.A. Olarewaju, S.O., Adeomi, A.A., Akande, J.O., Sola, S.T., Olugbenga-Bello, A.I. and Bamidele, J.O. (2020) Cardiovascular Risk Factors in the Civil Service of Oyo State, South-Western Nigeria: An Epidemic with an Unmatched Response. World Journal of Cardiovascular Diseases, 10, 587-607. https://doi.org/10.4236/wicd.2020.108058

Received: July 11, 2020

Accepted: August 28, 2020

Published: August 31, 2020

Copyright $\odot 2020$ by author(s) and Scientific Research Publishing Inc. This work is licensed under the Creative Commons Attribution International License (CC BY 4.0)

http://creativecommons.org/licenses/by/4.0/ (c) (i) Open Access

\begin{abstract}
Background: Worldwide, the burden of cardiovascular (CV) risk factors is rising with devastating impacts on the productive workforce. In developing nations, it has further led to an unstable population pyramid as a result of premature deaths of her workforce leading to the continued tapering of the pyramidal apex. Inspite of this, many studies were conducted among the general population neglecting the local government civil servants who are seen as policy implementers. Therefore, the study assessed the pattern of CV risk factors in South-western Nigeria. Methods: A cross-sectional study was conducted among 260 local government workers selected by multistage sampling technique from July to September 2017. A pretested, interviewer-administered questionnaire was administered to obtain socio-demographic and behavioural information. Lipid analysis, anthropometric, blood pressure, fasting blood glucose measurements were done according to protocols. Data were analyzed using IBM SPSS version 25; bivariate analysis was done using Chi-square. Level of significance was at $5 \%$. Results: The mean age of respondents was $46.0 \pm 6.7$ years. The proportion of participants with good knowledge of risk factors was $57.7 \%$. The proportion of respondent with hypertension, visceral obesity, general obesity, diabetes, smoking and physical inactivity was $40.4 \%, 35.0 \%, 52.2 \%, 38.2 \%, 5.8 \%$ and $75.8 \%$ respectively. The prevalence of elevated total cholesterol ( $\uparrow$ TC), raised low-density lipoprotein
\end{abstract}


( $\uparrow$ LDLc), low high-density lipoprotein ( $\downarrow$ HDLc) and elevated triglycerides ( $\uparrow$ TGs) was $55.4 \%, 85.0 \%, 70.4 \%$ and $3.1 \%$ respectively. There was a higher proportion of elevated total cholesterol (TC) and LDLc among female respondents $(\mathrm{p}=0.002 ; \mathrm{p}=0.009)$. Senior cadre staff had a higher proportion of respondents with raised $\downarrow$ HDLc and $\uparrow$ TGs $(p=0.031 ; p=0.036)$. Age was associated with hypertension and was highest among respondents in $45-54$ years age category $(\mathrm{p}<0.001)$. Conclusion: The prevalence of $\mathrm{CV}$ risk factors was higher compared with other studies in Nigeria and Africa. The findings illuminated a poor response to the rising burden of $\mathrm{CV}$ risk factors despite interventions put in place. This underscores the need for holistic preventive and control strategies with a view to reducing the incidence of cardiovascular diseases in Nigeria.

\section{Keywords}

Cardiovascular Diseases, Risk Factors, Prevalence, Civil Servants, Nigeria

\section{Introduction}

The burden of cardiovascular (CV) risk factors has become a global issue that has drawn the attention of public health professionals due to its attendant medical conditions such as stroke and heart attack [1]. The burden of CV risk factors is on the upward trend while the issues of communicable diseases remain largely unresolved. The epidemiological transition from communicable to non-communicable diseases (NCDs) with cardiovascular diseases (CVDs) being the leading cause of death is a major challenge confronting sub-Saharan Africa [2].

As the epidemics progress, the social gradient also turns around with the poor becoming the most susceptible victims in both developed and developing countries. Sedentary lifestyles, tobacco use, dangerous use of alcohol and an unhealthy diet have become the most significant behavioural risk factors for cardiovascular diseases [3]. An individual's exposure to these behavioural risk factors is highly influenced by their socio-economic status and the environment in which they live or work [4].

Increased socio-economic conditions associated with lifestyle changes in the direction of a high energy diet and sedentary habits are part of the main contributors to the incremental trend in CVDs in the last century [5]. Poverty, lack of education and unplanned urbanization can also increase exposure to risk factors and in turn have a negative impact on cardiac health [6]. It has been documented that the prevention of a great percentage of CVDs was associated with a reduction of these CV risk factors [7].

Cardiovascular diseases have become a major public health problem in Nigeria and other parts of the world such as India and Saudi Arabia and it is characterized by high rates of disability and unnecessary deaths particularly in Nigeria [8] [9]. However, there is a myth in Nigeria that mortality whether sudden or 
protracted from myocardial infarction (heart attack) or stroke (brain attack) is commonly ascribed to spells on the families [9] [10]. Cardiovascular diseases can differ greatly across certain groups of the population. Particular populations may be exposed differentially to risk factors, lack of access to health care, unhealthy lifestyles or may be disadvantaged in some ways. Such inequalities may apply to women, migrants or other socio-cultural groups, including the civil servants.

In 2001, CVDs accountable for $29 \%$ of all mortalities and $14 \%$ of the 1.5 billion lost DALYs and by 2030, when the population is anticipated to attain 8.2 billion, $32.5 \%$ of all deaths will be as a result of CVDs [11]. Of an estimated 58 million deaths globally from all causes in 2005, CVDs accounted for $30 \%$ [12]. A national survey and recent research reports in Nigeria proved that the burden of CVDs is rising in all parts of Nigeria [13]. In south-western Nigeria, a prevalence of 50.5\% [14] and 40.8\% [15] were documented for hypertension while $38.3 \%$ [15] and $49.5 \%$ [15] were reported for obesity and hypercholesterolemia respectively. At the epicenter of it all, are the civil servants who patronize fast food vendors while at work, inevitably consuming high energy-dense foods. In addition, they frequently engage in sedentary-related activities such as frequent attendance at meetings, short-distance movement within the offices, prolonged sitting inside the air-conditioned offices, preparation of the budget and other mental activities.

This combination of unhealthy dietary habit and physical inactivity place them at greater risk of developing CVDs and its complications [16]. In addition to the high burden of CVDs, these diseases have been documented to produce devastating consequences on the productive workforce aged 35 - 65 years within the families and communities [17]. Adopting lifestyles and dietary habits resulting in a greater burden of $\mathrm{CV}$ risk factors have been suggested to be responsible for the high prevalence of CVDs in Nigeria [13].

Consequent to the above burden, a lot of interventions in form of awareness and screening of cardiovascular risk factors as well as prohibition of smoking and drinking were put in place in some parts of the country [18]. Recently, in Nigeria, Basic Health Care Provision Fund was introduced as a social security or intervention to achieve Universal Health Coverage [19]. The security is designed to be achieved through financial risk protection in access to health services for all Nigerians, particularly the poor and most vulnerable. To mitigate the impact of the rising $\mathrm{CV}$ risk factors, among other services rendered, is the incorporation of screening for non-communicable diseases as part of the health services under the financial risk protection. Therefore, this study was conducted to determine the current prevalence of cardiovascular risk factors among civil servants in Oyo State with a view to assessing the impacts of different strategies put together to reduce the increased prevalence of CVD risk factors witnessed overtime.

\section{Methods}

\section{Study location}

The study was conducted using civil servants working in the local government 
areas (LGAs) of Oyo State. Oyo State is one of the 36 states in Nigeria and situated in the South-western part of the country. There are 8,635,793 people in the state according to the projected 2019 population using a growth rate of $3.4 \%$ and 2006 population figure as the baseline [20]. The state is mainly populated by the Yorubas and some other ethnic groups. Yorubas are primarily agrarian but a substantial proportion of them live in densely populated urban areas where the majority of them were found to be artisans, traders and civil servants. Trading activities and civil service work are largely sedentary. In Nigeria, cardiologists are in short supply, including Oyo State and are 581,000 population to a cardiologist [21]. Oyo State has three tertiary health facilities, about 60 fast food joints and restaurants (registered) while many are unregistered, four stadia and three recreational facilities.

\section{Study design and population}

This was a descriptive cross-sectional study of civil servants in six selected local government areas (LGAs) of Oyo State between July and September 2017. The inclusion criteria were consenting civil servants working in the LGAs' secretariats in Oyo State at the time of the study. In addition, the civil servants who had worked in the LGA for at least one year were recruited for the study. The exclusion criteria were medically unfit persons with oedema, ascites or other chronic illnesses. Pregnant women and those who could not stand straight for weight and height measurement were also excluded.

\section{Sample size and sampling technique}

The minimum sample size required for the study was calculated using the formula

$$
n=\frac{Z_{\alpha}^{2} p(1-p)}{d^{2}}
$$

where:

$Z_{\alpha}=$ standard normal deviate, set at 1.96 (for $95 \%$ confidence interval)

$d=$ desired degree of accuracy (taken as 0.05 )

$p=$ prevalence of hypertension in a previous study in Delta State, Nigeria was $21.0 \%[22]$.

$$
n=\frac{1.962 * 0.21(1-0.21)}{0.052}=255
$$

The calculated minimum sample size was 255 . However $10 \%$ of the minimum sample size was added to adjust for anticipated non-response and improperly filled questionnaires, so 280 respondents were recruited.

A multi-stage sampling technique was used. Stage one: A list of LGAs was made in each of the three senatorial districts. Two LGAs were selected from each of the lists of the LGAs in each of the three senatorial districts by ballot making 6 LGAs in all. Stage two: Ballot technique was also used to randomly select 4 of the 8 departments that constitute each of the 6 selected LGAs. Proportional allocation was used to determine the number of respondents needed in each of the 6 
selected LGAs. Stage three: The respondents were selected using systematic sampling and this was achieved with the aid of staff nominal list retrieved from the selected departments of each LGA.

\section{Research instruments and data collection methods}

Information about the respondents was captured using a semi-structured interviewer-administered questionnaire adapted from the WHO STEPS instrument [23]. To reflect local context, other questions developed from previous local studies were added to supplement the WHO STEPS questionnaire [14] [24]. Data on socio-demographic characteristics, behavioural risk factors and knowledge of cardiovascular risk factors were collected using the questionnaire. Anthropometric measurements were done using a digital bathroom weighing scale (SECA Clara 803 weight Scale, GmbH \& Co, Germany) for weight measurement, stadiometer (SECA 213 Height Measure, Leicester, UK) to measure height to the nearest $0.1 \mathrm{~m}$ and non-elastic tape measure (Goldfish brand) was used to measure waist and hip circumference. All measurements were carried out in line with recommended standard guidelines [25].

The blood pressure of respondents was measured using OMRON 2 digital sphygmomanometer. It was taken on the left arm of the respondents having had 10 to 15 minutes of rest in the sitting position. The cuffs were applied on the bare upper arm and closely fitted around it, with the lower edge $2.5 \mathrm{~cm}$ above the elbow joint. The cubital fossa was nearly at heart level. The reported blood pressure was an average of two measurements taken 10 to 15 mins apart.

Reminder in the form of text messages and phone calls were put across to remind them of overnight fasting for the lipid analysis. After overnight fasting (8 $12 \mathrm{~h}$ ), blood samples $(10 \mathrm{mls})$ were collected on the spot from respondents and divided into lithium heparinized and flouride oxalate bottles from respondents. During blood samples collection, standard infection prevention procedures were applied and adhered to. The collected blood samples were centrifuged at $5000 \mathrm{~g}$ for 10 minutes. Plasma obtained from the centrifuged blood sample was stored at $-20^{\circ} \mathrm{C}$ in cryovials until assayed. Estimation of the lipid profile was done by enzymatic techniques with Randox Kits using Semi-autoanalyzer (Clinical Chemistry Analyzer, HA-1900 by HAWSDEY). Glucose Oxidase method using Randox Kits was used to estimate fasting plasma glucose.

Data collection was done using 9 trained nurses/midwives, Community Health Extension Workers (CHEWs) and Medical Laboratory Scientists to assist in data collection. They were trained on blood sample collection and questionnaire administration for three days for 2 hours daily by the principal investigator. The content of the training has to do with demonstrations on the effective use of the data capturing tools. Chemical pathologist from LAUTECH Teaching Hospital, Ogbomoso, Oyo State was involved in the lipid profile analysis. The questionnaire was pretested among civil servants in LGAs different from the ones used for the main study. The pretest helped to assess the relevance of the questions in producing responses from the participants. Difficult questions were 
either removed or rephrased in line with the study objectives.

\section{Measurement of outcome variables}

A respondent was said to be hypertensive if diagnosed by a physician of hypertension, found to be using anti-hypertensive drugs, or had a systolic blood pressure (SBP) $\geq 140 \mathrm{mmHg}$ and/or a diastolic blood pressure $\geq 90 \mathrm{mmHg}$ [26]. Diabetes mellitus was documented if a respondent has been previously diagnosed by a physician, was using blood sugar lowering medications, or with a fasting blood glucose of $\geq 126 \mathrm{mg} / \mathrm{dL}$ [27].

A respondent was said to be obese when the BMI is $\geq 30 \mathrm{~kg} / \mathrm{m}^{2}$. The use of tobacco was categorized as non-smokers and ever smoked. Respondents with physical activity greater than or equal to three times per week of 30 minutes per occasion were classified as physically active [28]. A Waist circumference of greater than $88 \mathrm{~cm}$ in females and greater than $102 \mathrm{~cm}$ in males [29] was taken as visceral obesity. Any male and female respondent with Waist-hip ratio (WHR) of greater than 0.90 and 0.85 respectively were considered to be abnormal [29].

The knowledge of respondents on CVD risk factors was assessed with 10 questions. The total obtainable score was 10 and the mean score was 6 . An individual score above or equal to mean score was regarded as good knowledge. Level of significance was set at $\mathrm{p}<0.05$ for this study.

\section{Data analysis}

Statistical Package for Social Sciences (SPSS) version 24 (SPSS Inc, Chicago, IL, IBM Version) was used for entry and analysis. In the first instance, the univariate analysis of the variables was done. Presentations of data were carried out using frequency distribution tables and charts. Test of the association was done between categorical variables using Chi-square. Fisher's Exact Test was used to determine the statistical significance when the expected value of any cell was less than 5 .

\section{Ethical considerations}

Ethical approval for the study was obtained from the Ethical Review Committee, LAUTECH Teaching Hospital, Ogbomoso (No: LTH/OGB/EC/2016/101). Before enrolling any respondent into the study, written informed consent was obtained. Participation in the study was voluntary. Codes were used rather than participants' names as identifiers to ensure utmost confidentiality. Data were put in a passworded file and stored in a computer that was only accessible to the principal investigator. Study participants detected to have high cardiovascular risk factors were appropriately counseled and referred to the specialists for expertise management.

\section{Results}

A total of two hundred and eighty (280) questionnaires were administered, 260 were completely filled and returned giving a response rate of $92.9 \%$.

Socio-demographic characteristics of the local government employees in Oyo State, 2017

The majority (54.2\%) of the respondents were in the 45 - 54 years age category 
with an equal proportion of male and female respondents. Majority of the respondents were married (88.1\%) and had tertiary education (76.2\%) while about two-third were urban dwellers. The majority (82.7\%) of respondents had spent more than 10 years in the civil service while $93.1 \%$ of them received monthly income above minimum wage $(\mathrm{N} 18,000=\$ 47 \mathrm{USD})$. The proportion of respondents with poor knowledge was $42.3 \%$ (Table 1 ).

Table 1. Socio-demographic characteristics of the local government employees, Oyo State, 2017.

\begin{tabular}{|c|c|c|}
\hline Variables & Frequency & Percentage \\
\hline \multicolumn{3}{|l|}{ Age } \\
\hline$<35$ & 15 & 5.8 \\
\hline $35-44$ & 78 & 30.0 \\
\hline $45-54$ & 141 & 54.2 \\
\hline$>54$ & 26 & 10.0 \\
\hline \multicolumn{3}{|l|}{ Gender } \\
\hline Male & 128 & 49.2 \\
\hline Female & 132 & 50.8 \\
\hline \multicolumn{3}{|l|}{ Marital Status } \\
\hline Single & 11 & 4.2 \\
\hline Married & 229 & 88.1 \\
\hline Widowed & 13 & 5.0 \\
\hline Divorced/Separated & 7 & 2.7 \\
\hline \multicolumn{3}{|l|}{ Educational Level } \\
\hline Primary & 17 & 6.5 \\
\hline Secondary & 45 & 17.3 \\
\hline Tertiary & 198 & 76.2 \\
\hline \multicolumn{3}{|l|}{ Monthly Income } \\
\hline$<\mathrm{N} 18,000$ & 18 & 6.9 \\
\hline$\geq \mathrm{N} 18,000$ & 242 & 93.1 \\
\hline \multicolumn{3}{|l|}{ LGA Location } \\
\hline Urban & 163 & 62.7 \\
\hline Rural & 97 & 37.3 \\
\hline \multicolumn{3}{|c|}{ Number of Years in Service } \\
\hline$\leq 10$ & 45 & 17.3 \\
\hline$>10$ & 215 & 82.7 \\
\hline \multicolumn{3}{|c|}{ Knowledge of CVD Risk Factors } \\
\hline Poor & 110 & 42.3 \\
\hline Good & 150 & 57.7 \\
\hline
\end{tabular}


Association between gender and CVD risk factors among LGA employees, Oyo State, 2017

The proportion of respondents with elevated waist circumference was significantly higher (60.6\%) among female employees compared with their male counterparts $(p<0.001)$. High waist-hip-ratio was reported to be higher $(75.0 \%)$ among female respondents compared with male respondents $(\mathrm{p}=0.041)$. Only male respondents were smokers $(\mathrm{p}<0.001)$ while a higher proportion $(43.8 \%)$ of male respondents consumed alcohol compared with female respondents $(\mathrm{p}<$ 0.001). A higher proportion (60.2\%) of respondents with obesity was reported among male respondents compared with their female counterparts $(\mathrm{p}<0.001)$. The proportion of female respondents with hypertension was significantly higher $(59.0 \%)$ compared with their male counterparts $(\mathrm{p}=0.010)$ (Table 2$)$.

Lipid profile analysis stratified by gender of the LGA employees, Oyo State, 2017

The prevalence of elevated low-density lipoprotein was significantly higher (90.7\%) among female employees compared with male respondents $(\mathrm{p}=0.002)$. The proportion of respondents with elevated total cholesterol was higher among female (62.3\%) LGA employees compared with male respondents $(\mathrm{p}=0.009)$ (Figure 1).

Lipid profile analysis stratified by staff cadre of the LGA employees in Oyo State, 2017

Senior cadre has significant higher proportion (77.7\%) of respondents with low HDLc compared with junior cadre counterparts $(\mathrm{p}=0.036)$. The proportion of respondents with elevated triglycerides was significantly higher among senior cadre $(5.4 \%)$ compared with junior cadre staff $(p=0.031)$. However, no such significant association existed between staff cadre and other lipid components (Figure 2).

Prevalence of CV risk factors stratified by age of LGA employees in Oyo State, 2017

The proportion of respondents with hypertension was highest in the 45 - 54 age category $(\mathrm{p}<0.001)$ while elevated LDLc was prevalent $(100.0 \%)$ among those in the age 54 years and above $(p=0.011)$. The proportion of respondents with diabetes was highest in the age group $35-44$ years. However, this was not significant $(\mathrm{p}=0.325)($ Table 3$)$.

\section{Discussion}

The productive workforce has now become the target of the CVDs worldwide, especially in the developing African countries where poor health infrastructure dominates the continent profile. The effects of CVDs are not only felt on the health of the population but it is known to negatively impact the economy as a result of premature deaths of its hitherto healthy workforce. To reverse the fatality from the CVDs, it is incumbent to know the prevalence of cardiovascular risk factors with a view to preventing the occurrence of CVDs and associated complications. 
Table 2. Association between gender and CVD risk factors among LGA employees, Oyo State, 2017.

\begin{tabular}{|c|c|c|c|c|}
\hline \multirow{2}{*}{ Variables } & \multicolumn{2}{|c|}{ Gender } & \multirow{2}{*}{ Total } & \multirow{2}{*}{$P$ value } \\
\hline & Male & Female & & \\
\hline \multicolumn{5}{|c|}{ Age as at last birthday } \\
\hline$<35$ & $7(5.5)$ & $8(6.1)$ & $15(5.8)$ & 0.513 \\
\hline $35-44$ & $40(31.3)$ & $38(28.8)$ & $78(30.0)$ & \\
\hline $45-54$ & $65(50.8)$ & $76(57.6)$ & $141(54.2)$ & \\
\hline$>54$ & $16(12.5)$ & $10(7.6)$ & $26(10.0)$ & \\
\hline \multicolumn{5}{|c|}{ Waist circumference } \\
\hline High & $11(8.6)$ & $80(60.6)$ & $91(35.0)$ & ${ }^{*}<0.001$ \\
\hline Normal & $117(91.4)$ & $52(39.4)$ & $169(65.0)$ & \\
\hline \multicolumn{5}{|c|}{ Waist-Hip-Ratio } \\
\hline High & $81(63.3)$ & $99(75.0)$ & $180(69.2)$ & ${ }^{\star} 0.041$ \\
\hline Normal & 47 (36.7) & $33(25.0)$ & $80(30.8)$ & \\
\hline \multicolumn{5}{|l|}{ Smoking } \\
\hline Yes & $15(100.0)$ & $0(0.0)$ & $15(5.8)$ & ${ }^{* *}<0.001$ \\
\hline No & $113(46.1)$ & $132(53.9)$ & $245(94.2)$ & \\
\hline \multicolumn{5}{|c|}{ Ever taken alcohol } \\
\hline Yes & $56(43.8)$ & $13(9.8)$ & $69(26.5)$ & ${ }^{*}<0.001$ \\
\hline No & $72(56.3)$ & $119(90.2)$ & $191(73.5)$ & \\
\hline \multicolumn{5}{|c|}{ Physical activity } \\
\hline Active & $26(20.3)$ & $37(28.0)$ & $63(24.2)$ & 0.146 \\
\hline Inactive & $102(79.7)$ & $95(72.0)$ & $197(75.8)$ & \\
\hline \multicolumn{5}{|c|}{ Body Mass Index } \\
\hline Obese & $77(60.2)$ & 47 (35.6) & $136(52.3)$ & ${ }^{*}<0.001$ \\
\hline Non-obese & $51(39.8)$ & $85(64.4)$ & $124(47.7)$ & \\
\hline \multicolumn{5}{|l|}{ Diabetes } \\
\hline Yes & 47 (36.7) & $52(39.4)$ & $99(38.1)$ & 0.657 \\
\hline No & $81(63.3)$ & $80(60.6)$ & $161(61.9)$ & \\
\hline \multicolumn{5}{|l|}{ Hypertension } \\
\hline Yes & $34(31.2)$ & $71(47.0)$ & $105(40.4)$ & ${ }^{\star} 0.010$ \\
\hline No & $75(68.8)$ & $80(53.0)$ & $155(59.6)$ & \\
\hline \multicolumn{5}{|c|}{ Knowledge of $\mathrm{CV}$ risk factors } \\
\hline Poor & $44(40.4)$ & $66(43.7)$ & $110(42.3)$ & 0.590 \\
\hline Good & $65(59.6)$ & $85(56.3)$ & $150(57.7)$ & \\
\hline \multicolumn{5}{|l|}{ Staff Cadre } \\
\hline Senior & $62(56.9)$ & $68(45.0)$ & $130(50.0)$ & 0.059 \\
\hline Junior & $47(43.1)$ & $83(55.0)$ & $130(50.0)$ & \\
\hline
\end{tabular}

* Significant, ${ }^{* *}$ Fisher's Exact Test. 


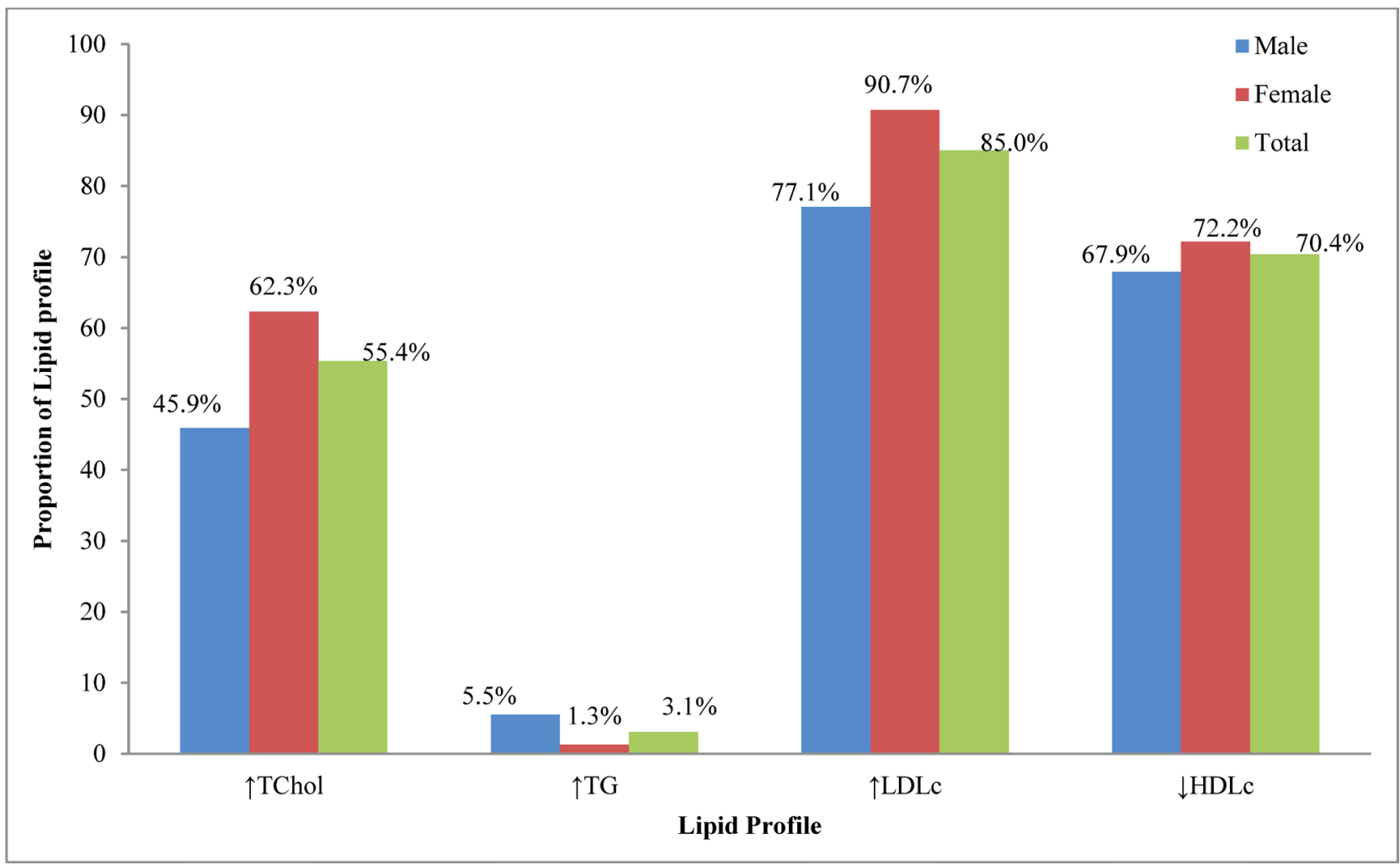

Figure 1. Lipid profile analysis stratified by gender of LGA employees in Oyo State, 2017.

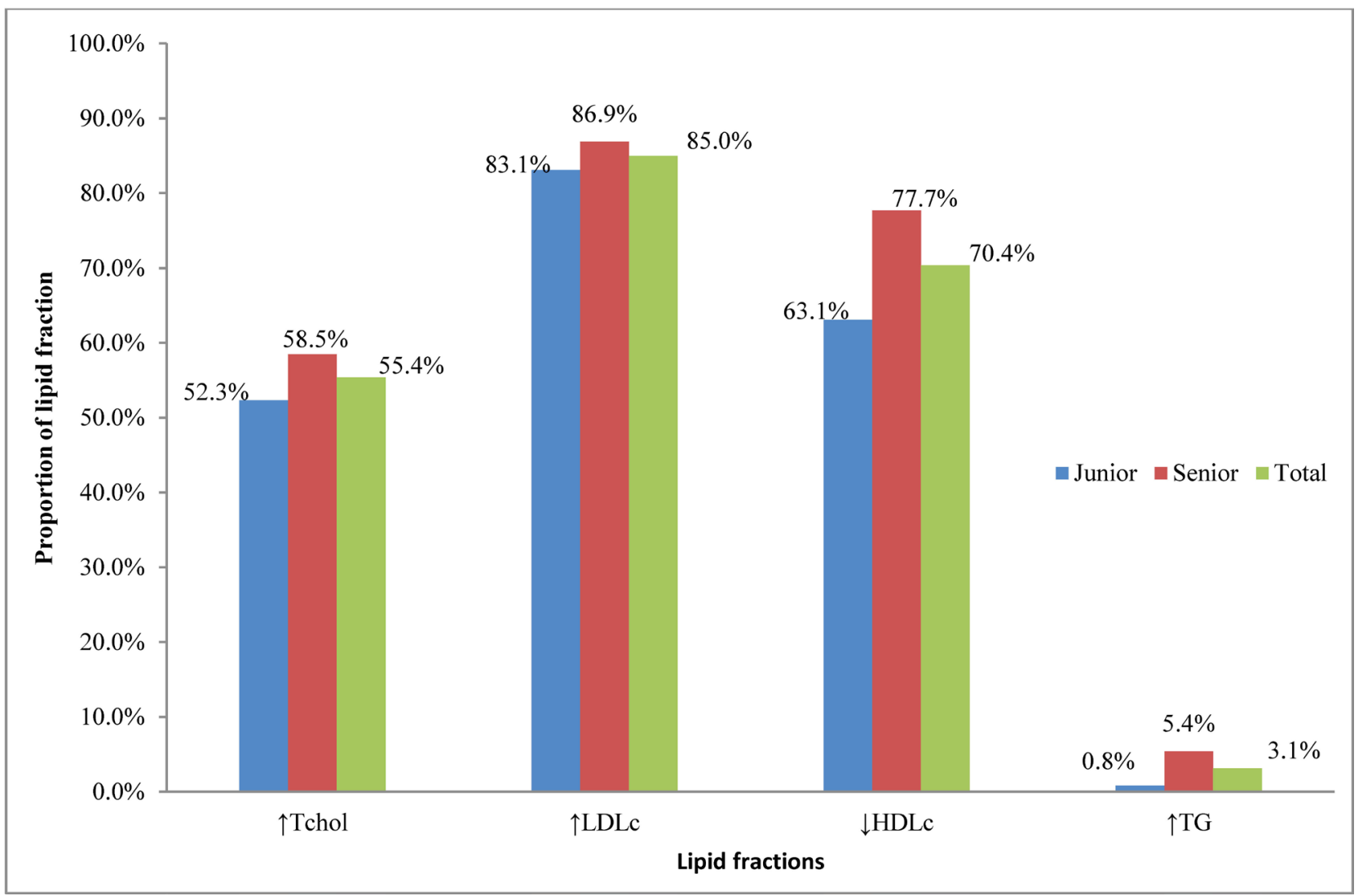

Figure 2. Lipid profile analysis stratified by staff cadre of LGA employees in Oyo State, 2017. 
Table 3. Prevalence of CV risk factors stratified by age of LGA employees in Oyo State, 2017.

\begin{tabular}{|c|c|c|c|c|c|}
\hline \multirow{2}{*}{ Variables } & \multicolumn{4}{|c|}{ Age (in years) $\mathrm{n}(\%)$} & \multirow{2}{*}{$P$ value } \\
\hline & $<35$ & $35-44$ & $45-54$ & $\geq 54$ & \\
\hline \multicolumn{6}{|c|}{ Waist circumference } \\
\hline High & $4(26.7)$ & $24(30.8)$ & $53(37.6)$ & $10(38.5)$ & 0.654 \\
\hline Normal & $11(73.3)$ & $54(69.2)$ & $88(62.4)$ & $16(61.5)$ & \\
\hline \multicolumn{6}{|l|}{ Diabetes } \\
\hline Yes & $5(33.3)$ & $33(42.3)$ & $55(39.0)$ & $6(23.1)$ & 0.325 \\
\hline No & $10(66.7)$ & $45(57.7)$ & $86(61.0)$ & $20(76.9)$ & \\
\hline \multicolumn{6}{|c|}{ Hypertension } \\
\hline Yes & $1(6.7)$ & $17(21.8)$ & $67(47.5)$ & $6(23.1)$ & ${ }^{*}<0.001$ \\
\hline No & $14(93.3)$ & $61(78.2)$ & $74(52.5)$ & $20(76.9)$ & \\
\hline \multicolumn{6}{|c|}{ Triglycerides } \\
\hline High & $0(0.0)$ & $4(5.1)$ & $4(2.8)$ & $0(0.0)$ & 0.488 \\
\hline Normal & $15(100.0)$ & $74(94.9)$ & $137(97.2)$ & $26(100.0)$ & \\
\hline \multicolumn{6}{|c|}{ Total cholesterol } \\
\hline High & $6(40.0)$ & $40(51.3)$ & $82(58.2)$ & $16(61.5)$ & 0.423 \\
\hline Normal & $9(60.0)$ & $38(48.7)$ & $59(41.8)$ & $10(38.5)$ & \\
\hline \multicolumn{6}{|l|}{ HDLc } \\
\hline Low & $9(60.0)$ & $55(70.5)$ & $104(73.8)$ & $15(57.7)$ & 0.087 \\
\hline Normal & $6(40.0)$ & $17(21.8)$ & $30(21.3)$ & $11(42.3)$ & \\
\hline High & $0(0.0)$ & $6(7.7)$ & $7(5.0)$ & $0(0.0)$ & \\
\hline \multicolumn{6}{|l|}{ LDLc } \\
\hline High & $14(93.3)$ & $62(79.5)$ & $119(84.4)$ & $26(100.0)$ & ${ }^{*} 0.011$ \\
\hline Normal & $1(6.7)$ & $16(20.5)$ & $22(15.6)$ & $0(0.0)$ & \\
\hline
\end{tabular}

${ }^{*}$ Fisher's Exact Test.

Consequent to this, the study assessed the pattern of cardiovascular risk factors in a group that is viewed to be prone to cardiovascular diseases (CVDs). More than half of the respondents belonged to the 45 - 54 years age category. This was expected as last recruitment into the local government areas was officially done in 2008 by Oyo State Local Government Service Commission (OYLGSC). The majority of the respondents had spent more than 10 years in service and this has justified their use as the study population. Long years of service are known to expose workers to the hazards of job and this could lead to the emergence of cardiovascular risk factors [16]. Majority of the respondents received far more than the minimum wage (\$47USD) and this could invariably expose them to fast foods while at work, inevitably consuming high energy-dense foods and drinks. In this regard, health education on the effects of 
consuming unhealthy diets will go a long way to reduce the incidence or prevalence of the CV risk factors.

This study revealed a significant proportion of respondents with a high prevalence of CV risk factors. The prevalence of hypertension recorded for the local government employees was $40.4 \%$ and was higher among respondents in 45 - 54 age category. This was in complete agreement with $40.8 \%$ documented by Akintunde, Salawu and Opadijo in Ogbomoso, Oyo State [15] and higher than 29.0\%, $28.1 \%$ and $27.9 \%$ reported in other studies in Nigeria [30] [31] and Ghana [32] respectively. The higher prevalence could result from the use of a high-risk population of civil servants compared with the use of the general population in the three studies. However, the prevalence of hypertension in our study was lower than 50.5\% reported in the same Ogbomoso, Oyo State [14]. The higher prevalence reported in Ogbomoso study could probably be due to the use of patients as a study population. This study also reported a male preponderance of hypertension and this was in agreement with a Belgian study [33]. This could result from the wide gender gap noticed in the educational system in Africa, including Nigeria [34]. In Africa, the pendulum of education and school enrolment is tilted towards the male gender and this could probably be the reason for the preponderance of male respondents in our study.

In light of this, efforts should be geared towards reducing the high prevalence of hypertension with a view to decreasing the mortality and disability in this productive group. This could be achieved through programmes targeting risk factors prevention as well as using low-cost management strategies. With the current global financial crisis, it then means that public health intervention must be prioritized for this set of workers, most especially among the male respondents, if the economy of the country must be sustained and improved upon.

The prevalence of general obesity in this study was $52.3 \%$ and it was higher among male respondents. Our findings corroborated the reported male preponderance of obesity in a study conducted in Imo State, Nigeria [35]. However, this negates what was reported by Sani et al. in Katsina, Nigeria where female respondents had a higher prevalence of general obesity than male counterparts [36]. The higher prevalence could be associated with higher physical inactivity, alcohol consumption and senior cadre status recorded among male respondents in this study.

In this study, there was a high prevalence of visceral obesity. The prevalence of visceral obesity was $35.0 \%$ and this agreed with a study in Spain which reported a similar finding in 2016 [37]. A higher prevalence was recorded among the university staff in Oyo State [15] while a lower prevalence was documented in Abia state [38]. The higher prevalence could probably result from the high socio-economic status of the lecturers studied in the university while lower prevalence could be due to the use of the general population as against high-risk population of civil servants in the present study. The prevalence was higher in female than their male counterparts. The higher prevalence of female obesity 
reported in this study was in line with the work of Ajani et al. in Lagos, Nigeria [39] and Amole, OlaOlorun and Owolabi in Oyo State, Nigeria [14].

The continued increasing pattern of obesity may generally reflect the nutritional transition being reported in developing countries, where lifestyle changes in the direction of a high energy diet and sedentary habits are taking an upward turn [5]. This may be the probable reason why the prevalence rate of obesity that was reported in this study almost doubles the findings in the same Oyo State six years ago [14]. However, it may just be a reflection of the socio-economic status of the different study areas [24].

Previous study had shown that weight loss of about $10 \%$ is consistent with about $35 \%$ reduction in visceral fat [40]. Although, the routine measurement of visceral fat is difficult to embark on, it was reported that waist circumference is strongly correlated with visceral fat [41] and such, decrease in waist circumference is associated with the corresponding decrease in visceral fat in a dose-response manner [41]. Arising from the high waist circumference reported in this study, it is recommended that waist circumference should be a routine measure in clinical practice to stratify health risk and more importantly, to follow the success of interventions designed to reduce obesity and related co-morbid conditions.

In this study, the prevalence of total cholesterol was $55.4 \%$ with higher proportion reported among female respondents and this was higher than $31.7 \%$ reported in rural communities in Edo State, Nigeria [42]. The higher prevalence could result from high physical inactivity and diabetes recorded in this study. Diabetes has been found to increase the prevalence of dyslipidemia [43]. However, the prevalence recorded in this study was lower than $60.0 \%, 60.4 \%, 69.9 \%$ reported for studies in South-south, Nigeria [44] [45] [46]. The high prevalence in these studies might be due to the use of professionals, women and elderly as study populations respectively.

Low-density Lipoprotein (LDLc) was found to be the most prevalent $(85.0 \%)$ dyslipidaemia and this finding was in tandem with the work of Ogbera [47] who also found LDLc as the most prevalent dyslipidaemia. This finding negates the outcome of different studies which reported a lower prevalence of LDLc [36] [48]. The variation recorded could have been from the socio-economic backgrounds of the populations studied. The higher prevalence of LDLc among female respondents and senior cadre staff in this study could be inferred from the higher prevalence of diabetes, obesity and physical inactivity noticed in them and this corroborated with what was reported in Abia state, Nigeria [49] and Japan [50]. Triglyceride is a significant finding in this study with a higher prevalence among the senior cadre staff. This was in agreement with the work of Justin et al. [51] who reported a similar difference in the two groups. On the contrary, triglycerides were marginally higher among senior staff compared with the junior staff as reported by Bunker et al. among the lean black populations [52]. The variation in the difference could probably result from different populations 
studied.

Dyslipidaemia was a significant feature in the present study, the plasma lipid profile was worse than many previous studies [36] [44] [45] [46] [48]. It may be argued that our study population, in general, may be at risk of CVDs. Therefore, interventions targeting at reducing the prevalence of dyslipidemia should be encouraged, most especially among female and senior staff respondents.

\section{Conclusion}

The prevalence of CV risk factors was higher compared with other studies in Nigeria [14] [15] [53] [54]. Despite the efforts put in place to control the rising burden of $\mathrm{CV}$ risk factors, the findings illuminated a poor response to a rising burden of CV risk factors among local government employees in Oyo State. This underscores the need for holistic preventive and control strategies with a view to reducing the incidence of cardiovascular diseases in Nigeria.

\section{Study Limitation}

This study was limited by the number of respondents interviewed. Self-administered questionnaire was used to collect information on behavioural attributes; therefore, the reliability of the responses given could not be much ascertained. However, to ensure the supply of correct information, the benefits of the study were painstakingly explained to the respondents.

\section{Acknowledgements}

The authors appreciate the support and cooperation of the Directors of Primary Health Care, Heads of Local Government Administration and the Local Government Staff of Oriire, Ogbomoso South, Ogo-Oluwa, Surulere, Ibadan North-East and Ibadan South-West LGAs for their participation and active involvement in the study.

\section{Declarations}

\section{Ethical Approval and Consent to Participate}

We obtained the approval for the study from the Ethical Review Committee, LAUTECH Teaching Hospital, Ogbomoso, Oyo State (No: LTH/OGB/EC/2016/101). We informed all the respondents about the study protocols and adherence to confidentiality. Before participation was allowed, written Informed consent was obtained from all the participants.

\section{Consent for Publication}

Not applicable.

\section{Availability of Data and Materials}

Upon demand, we can offer onsite access to external researchers to the data ana- 
lyzed at the Department of Community Medicine, LAUTECH Teaching Hospital, Ogbomoso, Nigeria. To do so, Dr. Olaniyan Akintunde Babatunde should be contacted.

\section{Funding}

No financial support was received for this research.

\section{Authors' Contributions}

$\mathrm{OAB}$ conceptualized the study, SOO, AAA and JOB contributed to the design, JOA supervised laboratory analysis, $\mathrm{OAB}$ drafted the initial manuscript, $\mathrm{OAB}$, OS, AAA, JOA, STS, AIB and JOB contributed to the analysis, interpretation of the results and made substantial revision to the initial draft. All authors read and approved the final version of the manuscript.

\section{Conflicts of Interest}

The authors declare no conflicts of interest regarding the publication of this paper.

\section{References}

[1] World Health Report 2002. Reducing Risks, Promoting Healthy Life. World Health Organization, Geneva, 7-14.

[2] World Health Report 2004. The Global Burden of Disease. Geneva, World Health Organization.

[3] World Health Organization (WHO). Cardiovascular Diseases (CVDs). https://www.who.int/news-room/fact-sheets/detail/cardiovascular-diseases-(cvds)

[4] Falase, A.O., Oladapo, O.O. and Kanu, E.O. (2001) Relatively Low Incidence of Myocardial Infarction in Nigerians. Tropical Cardiology, 27, 45-47.

[5] Dominguez, L.J., Galioto, A. and Ferlisi, A. (2006) Aging, Lifestyle Modifications and Cardiovascular Disease in Developing Countries. The Journal of Nutrition, Health and Aging, 10, 143-149.

[6] Smith, S., Ralston, J. and Taubert, K. (2012) Urbanization and Cardiovascular Disease: Raising Heart-Healthy Children in Today's Cities. World Heart Federation. http://worldheart.org/urbanization

[7] Mendis, S., Puska, P. and Norrving, B. (2011) Global Atlas on Cardiovascular Disease Prevention and Control. World Health Organization, Geneva.

[8] Ogah, O.S., Okpechi, I., Chukwuonye I.I., Akinyemi, J.O. and Onwubere, B.J. (2012) Blood Pressure, Prevalence of Hypertension and Hypertension Related Complications in Nigerian Africans: A Review. World Journal of Cardiology, 4, 327-340. https://doi.org/10.4330/wjc.v4.i12.327

[9] Arodiwe, E.B., Ike, S.O. and Nwokediuko, S.C. (2009) Case Fatality among Hypertension-Related Admissions in Enugu, Nigeria. Nigerian Journal of Clinical Practice, 12, 153-156.

[10] Iloh, G.P., Ikwudinma, A.O. and Obiegbu, N.P. (2013) Obesity and Its Cardio-Metabolic Co-Morbidities among Adult Nigerians in a Primary Care Clinic of a Tertiary Hospital in South-Eastern Nigeria. Journal of Family Medicine and Prima- 
ry Care, 2, 20-26. https://doi.org/10.4103/2249-4863.109936

[11] Gaziano, T.A. and Gaziano, J.M. (2008) Epidemiology of Cardiovascular Diseases. In: Fauci, A.S., Braunwald, E., Kasper, D.L., Hauser, S.I., Longo, D.L., Jameson, J.L. and Loscalzo, J., Eds., Harrison's Principles of Internal Medicine, McGraw-Hill Medical, New York, 1375-1379.

[12] WHO (2005) Preventing Chronic Disease: A Vital Investment World Health Organization, Geneva.

[13] Kadiri, S. (2005) Tackling Cardiovascular Diseases in Africa. BMJ, 331, 711-712.

[14] Amole, I.O., Olaolorun, A.D. and Owolabi, A.O. (2011) Prevalence of Obesity and Hypertension among Adults in Ogbomoso, Nigeria. Internet Journal of Medical Update, 6, 9-14. https://doi.org/10.4314/ijmu.v6i2.68186

[15] Akintunde, A.A., Salawu, A.A. and Opadijo, O.G. (2014) Prevalence of Traditional Cardiovascular Risk Factors among Staff of Ladoke Akintola University of Technology, Ogbomoso, Nigeria. Nigerian Journal of Clinical Practice, 17, 750-755. https://doi.org/10.4103/1119-3077.144390

[16] Gyntelberg, F., Suadicani, P., Jensen, G., Schnohr, P., Netterstrom, B. and Kristensen, T.S. (1998) Job Strain and Cardiovascular Risk Factors among Members of the Danish Parliament. Occupational Medicine, 48, 31-36. https://doi.org/10.1093/occmed/48.1.31

[17] Song, X., Quek, R.G.W., Gandra, S.R., Cappell, K.A., Fowler, R. and Cong, Z. (2015) Productivity Loss and Indirect Costs Associated with Cardiovascular Events and Related Clinical Procedures. BMC Health Services Research, 15, Article No. 245. https://doi.org/10.1186/s12913-015-0925-X

[18] Oyeleye, A., DeAtley, T., Ogunlade,O., Esan, O., Ochefu, H., Uzzell, S., Camara, B. and Sebrie, E. (2018) Monitoring of Tobacco Advertising and Promotion in Lagos, Nigeria: Observational Assessment to Inform Proposed Regulations to the National Tobacco Control Act. Tobacco Induced Diseases, 16, A197.

[19] Uzochukwu, B., Onwujekwe, O. and Mbachu, C. (2015) Implementing the Basic Health Care Provision Fund in Nigeria: A framework for Accountability and Good Governance.

https://resyst.lshtm.ac.uk/sites/resyst/files/content/attachments/2018-08-22/Implementi ng\%20the\%20Basic\%20Health\%20Care\%20Provision\%20Fund\%20in\%20Nigeria.pdf

[20] Federal Republic of Nigeria Official Gazette (2009) Legal Notice on Publication of 2006 Census Final Results. Official Gazette, 96, B1-B42.

[21] Karen, S., Liesl, Z., Kleinloog, R., Doubell, A., Ebrhim, I., Essop,M., Kettles, D., Jankelow, D., Khan, S., Klug, E., Thornton, A., Lecour, S., Marais, D., Mpe, M., Ntsekhe, M., Chin, A., Osrin, L., Smit, F., Snyders, A., Theron, J.P., van der Merwe, N., Dau, E. and Sarkin, A. (2016) Cardiology-Cardiothoracic Subspeciality Training in South Africa: A Position Paper of the South Africa Heart Association. Cardio Vascular Journal of Africa, 27, 188-193.

[22] Ibekwe, R. (2015) Modifiable Risk Factors of Hypertension and Socio-Demographic Profile in Oghara, Delta State; Prevalence and Correlates. Annals of Medical and Health Sciences Research, 5, 71-77.

[23] WHO (2017) The WHO STEP Wise Approach to Noncommunicable Disease Risk Factor Surveillance.

https://www.who.int/ncds/surveillance/steps/STEPS_Manual.pdf?ua=1

[24] Karaye, K.M., Okeahialam, B.N. and Wali, S.S. (2009) Cardiovascular Topics Impact of Income on the Profile of Cardiovascular Risk Factors among Hypertensives in a Nigerian Tertiary Health Centre: A Cross-Sectional Study. Cardiovascular 
Journal of Africa, 20, 251-255.

[25] Stewart, A.D., Marfell-Jones, M., Olds, T. and De Ridder, J.H. (2001) International Standards for Anthropometric Assessment. International Society for the Advancement of Kinanthropometry, 53-55.

[26] Hendriks, M.E., Wit, F.W., Roos, M.T., Brewster, L.M., Akande, T.M. and Ingrid, H. (2012) Hypertension in Sub-Saharan Africa: Cross-Sectional Surveys in Four Rural and Urban Communities. PLoS ONE, 7, e32638. https://doi.org/10.1371/journal.pone.0032638

[27] Mendis, S. and Puska, P. (2011) Global Atlas on Cardiovascular Disease Prevention and Control. World Health Organization (in Collaboration with the World Heart Federation and World Stroke Organization), Geneva.

[28] Physical Activity and Health: A Report of the Surgeon General. US Department of Health and Human Services, Washington DC.

[29] World Health Organization (1999) Definition, Diagnosis, and Classification of Diabetes Mellitus and Its Complications: Report of a WHO Consultation. Part I: Diagnosis and Classification of Diabetes Mellitus. World Health Organization, Geneva.

[30] Oladimeji, A.M., Fawole, O., Nguku, P. and Nsubuga, P. (2014) Prevalence and Factors Associated with Hypertension and Obesity among Civil Servants in Kaduna, Kaduna State. Pan African Medical Journal, 18, Article No. 13. https://doi.org/10.11604/pamj.supp.2014.18.1.3260

[31] Wokoma, F.S. and Alasia, D.D. (2011) Blood Pressure Pattern in Barako-A Rural Community in Rivers State, Nigeria. The Nigerian Health Journal, 11, 8-13.

[32] Dosoo, D.K., Nyame, S., Enuameh, Y., Ayetey, H., Danwonno, H., Twumasi, M., Tabiri, C., Gyaase, S., Lip, G.Y.H., Owusu-Agyei, S. and Asante, K.P. (2019) Prevalence of Hypertension in the Middle Belt of Ghana: A Community-Based Screening Study. International Journal of Hypertensio, 2019, Article ID: 1089578. https://doi.org/10.1155/2019/1089578

[33] Shivaramakrishna, H.R., Wantamutte, A.S., Sangolli, H.M. and Mallapur, M.D. (2010) Risk Factors of Coronary Heart Disease among Bank Employees of Belgaum City - Cross-Sectional Study. Journal of Medicine, 3, 152-159.

[34] Akinbi, J.O. and Akinbi, Y.A. (2015) Gender Disparity in Enrolment into Basic Formal Education in Nigeria : Implications for National Development. African Research Review, 9, 11-23.https://doi.org/10.4314/afrrev.v9i3.2

[35] Oladipo, G.S., Osaat, R.S., Orluwene, C.G. and Suleman, Y.A. (2012) Body Mass Index and Waist-to-Hip Ratio among Adults of Obowo Nationality in Imo State, Nigeria. International Journal of Basic, Applied and Innovative Research, 1, 138-144.

[36] Sani, M.U., Wahab, K.W., Yusuf, B.O., Gbadamosi, M. and Johnson, O.V. (2010) Modifiable Cardiovascular Risk Factors among Apparently Healthy Adult Nigerian Population-A Cross Sectional Study. BMC Research Notes, 3, Article No.11. https://doi.org/10.1186/1756-0500-3-11

[37] Aranceta-Bartrina, J., Pérez-Rodrigo, C., Alberdi-Aresti, G. Ramos-Carrera, N. and Lázaro-Masedo, S. (2016) Prevalence of General Obesity and Abdominal Obesity in the Spanish Adult Population (Aged 25 - 64 Years) 2014-2015: The ENPE Study. Revista Española de Cardiología, 69, 579-587. https://doi.org/10.1016/j.recesp.2016.02.010

[38] Chukwuonye, I.I., Chuku, A., Onyeonoro, U.U., Okpechi, I.G., Madukwe, O.O., Umeizudike, T.I. and Ogah, O.S. (2013) Prevalence of Abdominal Obesity in Abia state, Nigeria: Results of a Population-Based House-to-House Survey. Diabetes, 
Metabolic Syndrome and Obesity: Targets and Therapy, 6, 285-291. https://doi.org/10.2147/DMSO.S43545

[39] Ajani, S.R., Holdbrooke, J., Abba, S. and Ariyo, O. (2015) Gender Differences in Factors Associated with Overweight and Obesity among Civil Servants in Lagos, Nigeria. International Journal of Nutrition and Metabolism, 7, 66-73. https://doi.org/10.5897/IJNAM2015.0187

[40] Janssen I, Ross R. (1999) Effects of Sex on the Change in Visceral, Subcutaneous Adipose Tissue and Skeletal Muscle in Response to Weight Loss. International Journal of Obesity, 23, 1035-1046. https://doi.org/10.1038/sj.ijo.0801038

[41] Ross, R., Rissanen, J. and Hudson, R. (1996) Sensitivity Associated with the Identification of Visceral Adipose Tissue Levels Using Waist Circumference in Men and Women: Effects of Weight Loss. International Journal of Obesity and Related Metabolic Disorders, 20, 533-538.

[42] Okaka, E, and Eiya, B.O. (2013) Prevalence and Pattern of Dyslipidemia in a Rural Community in Southern Nigeria. African Journal of Medical and Health Sciences, 12, 80-84.

[43] Isezuo, S.A., Badung, S.L. and Omotosho, A.B. (2003) Comparative Analysis of Lipid Profiles Among Patients with Type 2 Diabetes Mellitus, Hypertension and Concurrent Type 2 Diabetes, and Hypertension. A View of Metabolic Syndrome. Journal of the National Medical Association, 95, 328-334.

[44] Odenigbo, C.U., Oguejiofor, O.C., Odenigbo, U.M., Ibeh, C.C., Ajaero, C.N. and Odike, M.A.C. (2008) Prevalence of Dyslipidaemia in Apparently Healthy Professionals in Asaba, South South Nigeria. The Nigerian Journal of Clinical Practice, 11, 330-335.

[45] Agboola-Abu, C.F. and Onabolu, A. (2000) Plasma Lipid Levels in Patients Attending Igbinedion Hospital and Medical Research Centre, Okada, Edo State, Nigeria. Nigerian Medical Journal, 38, 1-5.

[46] Odenigbo, C.U., Odenigbo, U.M., Oguejiofor, O.C. and Okonkwo, N.I. (2010) Prevalence of Dyslipidaemia in Elderly Subjects in Asaba, South-South Nigeria. Journal of the Indian Academy of Geriatrics, 6, 160-164.

[47] Ogbera, A.O., Fasanmade, O.A., Chinenye, S., Akinlade, A. (2009) Characterization of Lipid Parameters in Diabetes Mellitus-A Nigerian Report. International Archives of Medicine, 2, 19. https://doi.org/10.1186/1755-7682-2-19

[48] Osuji, C.U., Nzerem, B.A., Meludu, S., Dioka, C.E., Nwobodo, E. and Amilo, G.I. (2014) The Prevalence of Overweight/Obesity and Dyslipidaemia amongst a Group of Women Attending “August” Meeting. Nigerian Medical Journal, 51, 155-159.

[49] Okafor, P.N., Ukegbu, P.O., Godfrey, O.C., Ofoegbu, M.C. and Uwaegbute, A.C. (2014) Assessment of Lipid Profile in Middle and Upper Class Individuals in Abia State, Nigeria Based on Life-Style and Dietary Habits. Journal of Medical and Biomedical Sciences, 3, 1-8.

[50] Oda, E., Abe, M., Kato, K., Watanabe, K., Veeraveedu, P.T. and Aizawa, Y. (2006) Gender Differences in Correlations Among Cardiovascular Risk Factors. Gender Medicine, 3, 196-205. https://doi.org/10.1016/S1550-8579(06)80208-1

[51] Justin, Z.M., Patel, A., Jan, S., Hillis, G.S., Raju, P.K., Neal, B.C. and Clara, K. (2012) Socio-Economic Distribution of Cardiovascular Risk Factors and Knowledge in Rural India. International Journal of Epidemiology, 41, 1302-1314. https://doi.org/10.1093/ije/dyr226

[52] Bunker, C.H., Ukoli, F.A., Okoro, F.I., Olomu, A.B., Kriska, A.M., Huston, S.L., 
Markovic, N. and Kuller, L.H. (1996) Correlates of Serum Lipids in a Lean Black Population. Atherosclerosis, 123, 215-225.

https://doi.org/10.1016/0021-9150(96)05810-8

[53] Abdulsalam, S., Olugbenga-Bello, A., Olarewaju, O. and Abdus-Salam, I. (2014) Sociodemographic Correlates of Modifiable Risk Factors for Oyo State South West Nigeria. International Journal of Hypertension, 2014, Article ID: 842028. https://doi.org/10.1155/2014/842028

[54] Amole, I.O., OlaOlorun, A.D., Odeigah, L.O. and Adesina, S.A. (2011) The Prevalence of Abdominal Obesity and Hypertension amongst Adults in Ogbomoso, Nigeria. African Journal of Primary Health Care \& Family Medicine, 3, 1-5.

https://doi.org/10.4102/phcfm.v4i1.188

\section{List of Abbreviations}

LGAs Local Government Areas

CVDs Cardiovascular Diseases

CHEWs Community Health Extension Workers

LAUTECH Ladoke Akintola University of Technology

LTH LAUTECH Teaching Hospital

WHO World Health Organization

TChol Total Cholesterol

LDLc Low Density Lipoprotein cholesterol

HDLc High Density Lipoprotein cholesterol

TGs Triglycerides

BMI Body Mass Index 


\section{Appendix}

\section{Questionnaire}

Cardiovascular risk factors in the civil service of Oyo State, South-western Nigeria: an epidemic with an unmatched response

\section{Participant Identification Number}

Section A Socio-demographic data. Tick appropriate answer or fill in the gap
1. Sex
Male [ ]
Female [ ]

If female, state date of your last menstruation

2. Age last birthday $\llcorner\perp$ Years

3. What is your religion?

Christianity [ ] Islam [ ]

Others specify

4. What is your tribe? Yoruba [ ]

5. What is your marital status? Single [ ] Hausa/Fulani [ ] Igbo [ ] Others specify

Divorced [ ] Married [ ] Widow [ ]

6. What is your highest educational qualification? Separated [ ]

Cohabitating [ ] Others [ ]

7. How many years have you spent in service?

8. What is your grade level?

9. What is your monthly income?

\section{SECTION B: KNOWLEDGE OF CARDIOVASCULAR RISK FACTORS}

\section{Assessment of knowledge of cardiovascular risk factors}

a If you have a family history of heart disease you are at risk for developing heart disease

b The older a person is, the greater their risk of having heart disease

c Smoking is a risk factor for heart disease

d High blood pressure is a risk factor for heart disease

e High cholesterol is a risk factor for developing heart disease

f Eating fatty foods does not affect blood cholesterol levels

g Being overweight increases a person's risk for heart disease

h Regular physical activity will lower a person's chance of getting heart disease

I Diabetes is a risk factor for developing heart disease

\section{SECTION C: Cardiovascular risk factors (Behavioural)}

\section{Smoking/Tobacco Use}

11. Have you ever smoked cigarette/use any tobacco products? Yes [ ] No [ ] If NO, go to question 14

12. When last did you smoke? [ ] days

13. How long have you been smoking?-----------/-----------months/years

\section{Alcohol consumption}


14. Have you ever consumed alcohol? Yes [ ] No [ ]

(I have never had a standard alcoholic drink in my life). Skip to 18

15. Did you take alcohol in the past 30 days? Yes [ ] No [ ]

16. How often do you drink alcohol?

17. On an average, how many bottles of beer/glass of alcoholic wine/shot of gin or whisky do you have in a day?

\section{Physical activity}

18. Does your work schedule involve vigorous-intensity activity that causes large increases in breathing or heart rate like [carrying or lifting heavy loads, digging or construction work] for at least 20 minutes continuously?

$$
\text { Yes ( ) No ( ) If NO go to } 21
$$

19. In a typical week, on how many days do you do vigorous-intensity activities as part of your work? Number of days L L

20. How much time do you spend doing vigorous-intensity activities at work on a typical day? Hours: minutes<smiles>ICC1CCC1CI</smiles>

21. Does your work involve moderate-intensity activity that causes small increases in breathing or heart rate such as brisk walking [or carrying light loads] for at least 30 minutes continuously?

\section{Yes( ) $\quad \mathrm{No}(\quad) \quad$ If NO go to 24}

22. In a typical week, on how many days do you do moderate-intensity activities as part of your work? Number of days

23. How much time do you spend doing moderate-intensity activities at work on a typical day? Hours: minutes ᄂـلـ : لــ

\section{Section D: Cardiovascular risk factors}

\section{Overweight/Obesity}

24. Height in Meters (m)

25. Weight in Kilograms (kg)

\section{Blood Pressure} Diastolic ( $\mathrm{mmHg}$ )

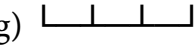

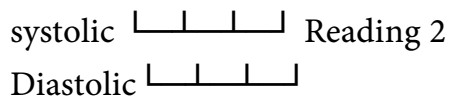

\section{Fasting Blood Glucose and Blood Lipids}

27. During the past 12 hours have you eaten or drunk anything? Yes [ ] No [ ]

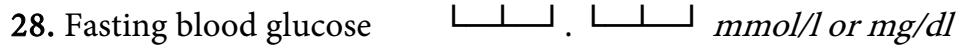

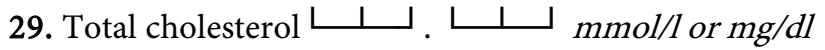

30. LDL Cholesterol $\downarrow \downarrow \mathrm{mmol} / \mathrm{l}$ or $\mathrm{mg} / \mathrm{dl}$

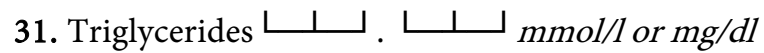

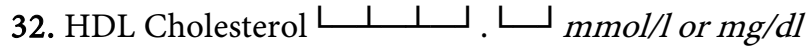

